\title{
Mielopatia por deficiência de cobre
}

\author{
José Maria Carri ${ }^{1}$, Alejandro Agustín Carri \\ Hospital Bandeirantes (Grupo Bandeirantes), São Paulo, SP, Brasil; Departamento de Ortopedia e Traumatologia do Hospital \\ das Clínicas da Faculdade de Medicina da Universidade de São Paulo (HC-FMUSP), São Paulo, SP, Brasil.
}

\section{RESUMO}

A deficiência de cobre (CU) adquirida ganha reconhecimento como causa de anemia e neutropenia. Na última década, ela é reconhecida como produtora de mielopatia ou mieloneuropatia degenerativa, que mimetiza a deficiência de vitamina de B12, podendo apresentar-se em concomitância com essa última. Foram discutidos etiologias, fisiopatologia, diagnósticos diferenciais e tratamentos, assim como achados radiológicos caraterísticos na ressonância nuclear magnética (RNM), principalmente na imagem ponderada T2, da medula cervical e dorsal, confrontando-as com dados laboratoriais direcionados à patologia, conseguindo-se maior acurácia diagnóstica. Observou-se que o diagnóstico precoce pode reverter a doença do ponto de vista laboratorial, de imagem e neurológico ou estabilizar a progressão. Sendo assim, recomendamos incluir na pesquisa laboratorial das cirurgias bariátricas, gastrectomias, síndromes de má-absorção e na administração oral de zinco (Zn).

\section{PALAVRAS-CHAVE}

Cobre, anemia mielopática, deficiência de vitamina B12, cirurgia bariátrica.

\section{ABSTRACT}

Cupper deficiency myelopathy

Acquired copper (Cu) deficiency has been recognized to promote anemia and neutropenia. During the last decade degenerative myelopathy or myeloneuropathy diseases that can be mimicked by vitamin $B 12$ deficiency or in another cases both of them (Cu and B12 deficiency) can coexist. We researched etiologies, physiopathology, differential diagnostic, treatment and radiologic findings in MRI, that showed high T2 signal in posterior cervical and thoracic cord and when assembled with laboratorial data we achieved accurate diagnostics. We observed that precocious diagnostic could revert the disease and improve neurologic deficit or stabilize its progression. However, we recommend laboratorial research in bariatric surgery, gastrectomy, malabsortion syndromes and high zinc levels administration.

\section{KEYWORDS}

Copper, myelophathic anaemia, vitamin B12 deficiency, bariatric surgery.

1 Médico neurocirurgião do Hospital Bandeirantes, São Paulo, SP, Brasil.

2 Médico-residente do Departamento de Ortopedia do Hospital das Clínicas da Faculdade de Medicina da Universidade de São Paulo (HC-FMUSP), São Paulo, SP, Brasil. 


\section{Introdução}

Reconhecida como patologia absortiva em ruminantes, produtora de anemia, neutropenia, mielopatia e mieloneuropatia, a deficiência de cobre vem ganhando terreno em humanos por causa de procedimentos cirúrgicos bariátricos, gastrectomias, patologias de origem absortiva e alterações do trânsito gastrointestinal. ${ }^{1-3}$

Observa-se, nos exames complementares pré ou pós-cirúrgicos das patologias acima detalhadas, a inexistência de pesquisa de dosagem de $\mathrm{Cu}$ e ceruloplasmina, o que excluiria uma das causas prováveis de mielopatia ou mieloneuropatia. Ao cursar paralelamente com deficiência de vitamina B12, pode levar, no longo prazo, a erros de diagnósticos e tratamentos. ${ }^{3,4}$

\section{Relato de caso}

Paciente do sexo feminino que em 2008 realizou cirurgia bariátrica para o tratamento de obesidade mórbida. Cooperativa no tratamento pós-cirúrgico, seguiu as recomendações clínicas relativamente a dietas, suplementos vitamínicos e medicamentos, e realizou exames laboratoriais periódicos.

Em 2009, apresentou queixa de dor lombar moderada com irradiação em membros inferiores, sem distribuição metamérica, referindo dores do tipo neuropático, principalmente distal, acompanhada de parestesias.

Realizou ressonância nuclear magnética (RNM) de coluna lombar com diagnóstico de hérnia discal 14-15 sem comprometimento radicular, com diminuição foraminal por artrose facetária. Submetida à descompressão radicular com artrodese de 14-15-S1.

Sem melhora e agravando-se a sintomatologia, ela procura uma segunda opinião, sofrendo intervenção cirúrgica novamente, com a finalidade de melhorar a descompressão radicular e o realinhamento de material de artrodese.

Imediatamente após o segundo procedimento, a paciente continua com queixas sensitivas, acrescentando diminuição de força bilateral em membros inferiores (MMII), estendendo-se a sintomatologia sensitiva parestésica nos membros superiores tipo luva. Dando seguimento ao tratamento com analgésicos e fisioterapia, no começo de 2011 observa-se piora na deambulação, acrescentando marcha atáxico-espástica.

Realizada RNM de coluna cervical, é indicado novo tratamento cirúrgico do segmento cervical (Figuras 1 e 2).

Procurando outra opinião, a paciente ingressa em nosso serviço com distúrbios na deambulação, interpre- tados como marcha sensitivo-atáxica de características espásticas, sensibilidade epicrítica e protopática comprometida, principalmente em MMII.

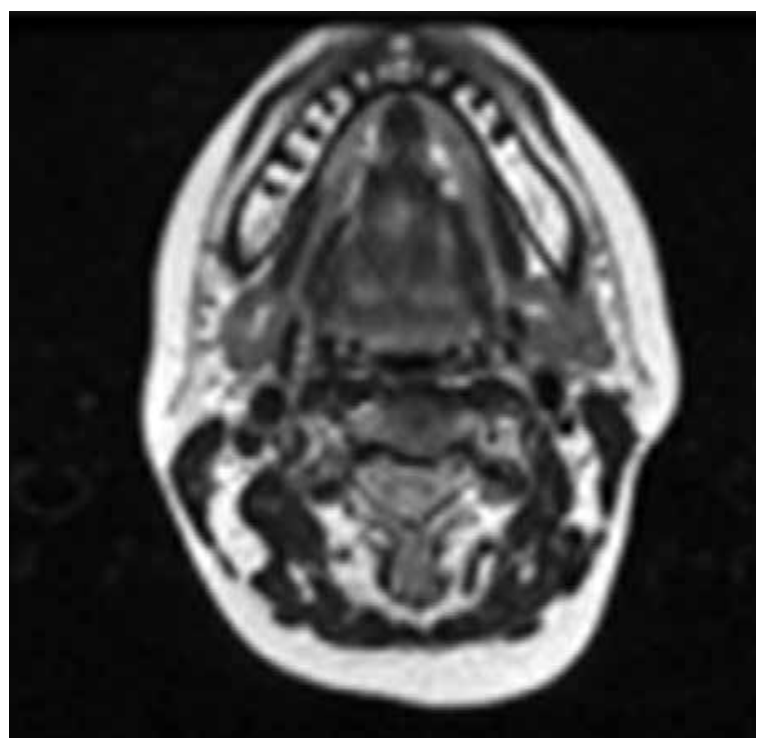

Figura 1 - RNM corte axial, imagem ponderada T2, mostra área hiperintensa comprometendo o cordão posterior.

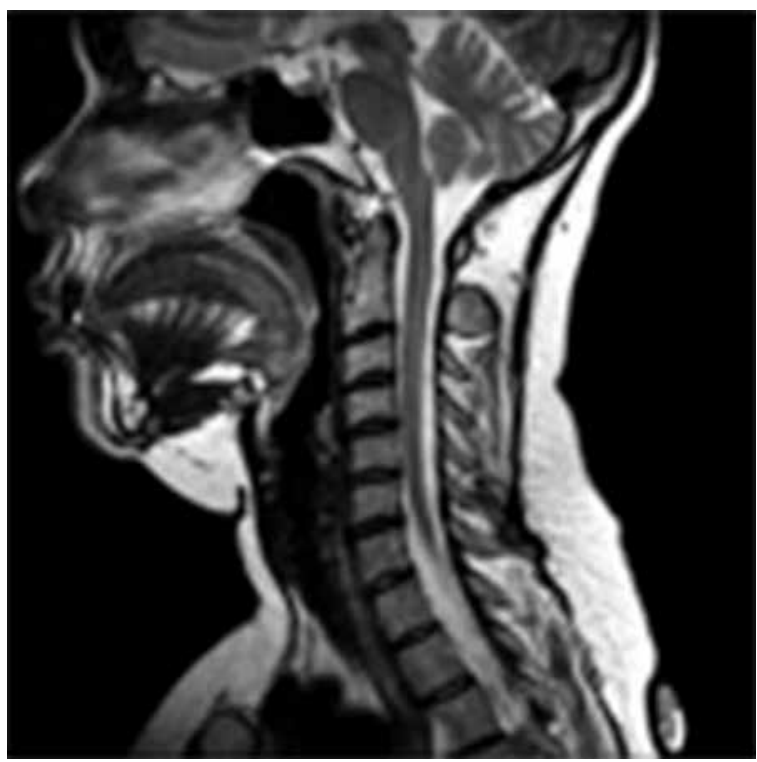

Figura 2 - RNM corte sagital, imagem ponderada T2, delimitando comprometimento cefalocaudal do trato posterior.

\section{Exame físico}

Parestesias, sensibilidade superficial e profunda comprometida em quatro membros, com preponderância em MMII. 
Reflexos profundos: hiper-reflexia patelar e aquiliana, clônus esgotável em MIE, aumento da base de sustentação, provas de dismetria positivas em ambos os membros inferiores.

Refere distúrbios esfincterianos, traduzidos como incontinência urinária evolutiva, porém não incapacitante.

Pela clínica e imagens obtidas, descartou-se procedimento cirúrgico do segmento cervical, dando início a processo investigativo laboratorial.

Laboratório - Hemograma completo: normal; vitamina B12: $332 \mathrm{pg} / \mathrm{ml}$; ácido fólico: 14,3 ng/ml; $\mathrm{Na}$ : $142 \mathrm{mEq} / \mathrm{l} ; \mathrm{K}: 4,1 \mathrm{mEq} / \mathrm{l}$; ferro: $81 \mu \mathrm{g} / \mathrm{dl}$; ferritina: 311 $\mathrm{ng} / \mathrm{ml}$; transferrina: $102 \mathrm{ng} / \mathrm{dl}$; hemoglobina glicada: $3,3 \%$; glicemia: $77 \mathrm{mg} / \mathrm{dl}$; ureia: $31 \mathrm{mg} / \mathrm{dl}$; creatinina: $0,71 \mathrm{mg} / \mathrm{dl}$.

Provas hepáticas - AST: 22 U/l; ALT: 16 U/l; GGT: 17 U/l; ALP: 109 U/l; amilase: 83 U/l; Bil: D 0,20, I $0,27, \mathrm{~T} 0,47$.

Pesquisa de hepatite A, B, C negativa.

Ac. antiLKM1, FAN, PCR, VHS: dentro da normalidade.

Provas de função tireóidea e paratireóidea: dentro da normalidade. Titulação de anticorpos antitireóideos: negativa.

Urina tipo l: dentro da normalidade.

RNM de coluna cervical: mostra área hiperintensa na fase ponderada $\mathrm{T} 2$, comprometendo trato posterior que não realça com contraste, descrito como mielite inespecífica (Figuras 1 e 2).

Consequentemente aos resultados radiológicos e laboratoriais, foram pesquisados distúrbios do metabolismo de $\mathrm{Cu}$.

Resultados: Cu 9,0 $\mu \mathrm{g} / \mathrm{dl}$ (80-155), ceruloplasmina $9,0 \mathrm{mg} / \mathrm{dl}$ (22-68), exames repetidos e confirmados valores em diferentes laboratórios.

Exame oftalmológico descarta anel de Kayser-Fleicher. ${ }^{3}$

Após 30 dias de evolução, modificados os suplementos alimentares, retirado o zinco da reposição alimentar e administrado Cobre Quelato em dose de $5 \mathrm{mg}$ ao dia, obtendo-se os seguintes resultados: cobre $57 \mu \mathrm{g} / \mathrm{dl}$ (80-155); zinco $81 \mu \mathrm{g} / \mathrm{dl}$; zinco urinário 144,1 $\mu \mathrm{g} / \mathrm{l}$ (180-850), PTH 43,6 pg/ml (12-65); hemograma completo normal (Tabela 1).

Em reavaliação com 60 dias de evolução, administrando-se Cobre Quelato $10 \mathrm{mg}$ ao dia, observa-se melhora da síndrome neurológica deficitária, encontrando como único sinal neurológico parestesias, predominantemente em MMII.

RNM de coluna cervical: considerada dentro da normalidade (Figura 3). Dosagem de $\mathrm{Cu}$ sanguíneo: $62 \mu \mathrm{g} / \mathrm{dl}$ (80-155), ceruloplasmina $22 \mathrm{mg} / \mathrm{dl}$ (20-60).

Continuando o tratamento com Cobre Quelato 20 $\mathrm{mg} / \mathrm{dia}$.

\begin{tabular}{|c|c|c|c|}
\hline \multicolumn{4}{|c|}{ Tabela 1 - Dados laboratoriais ao longo do tratamento } \\
\hline HEMOGRAMA & $15 / 7 / 11$ & 8/8/11 & $16 / 12 / 11$ \\
\hline Eritrócitos & 3,47 & 3,53 & \\
\hline Hemoglob. & 11,3 & 11,4 & \\
\hline Hct. & 34,3 & 35 & \\
\hline Leucócitos & 3820 & 5350 & \\
\hline Plaquetas & 205.000 & 207.000 & \\
\hline Vit. B12 & 257 & & \\
\hline \multicolumn{4}{|l|}{ Ac. fólico } \\
\hline \multicolumn{4}{|l|}{ PERFIL HEPÁTICO } \\
\hline Bil. direta & 0,2 & & \\
\hline Bil. indireta & 0,27 & & \\
\hline Total & 0,47 & & \\
\hline AST & 22 & & \\
\hline ALT & 16 & & \\
\hline GGT & 17 & & \\
\hline Amilase & 83 & & \\
\hline Fosf. alcalina & 109 & & \\
\hline \multicolumn{4}{|l|}{ PROTEINOGRAMA } \\
\hline Prot. totais & 6 & 6,5 & 7,3 \\
\hline Albumina & 2,9 & 3,6 & 3,8 \\
\hline Globulina & 3,1 & 2,9 & 3,5 \\
\hline \multicolumn{4}{|c|}{ P. REUMATOLÓGICAS } \\
\hline PCR & $>5$ & & \\
\hline VHS & 6 & & \\
\hline FAN & NEG. & & \\
\hline FR & $>11$ & & \\
\hline Ac. antiLKM1 & NEG. & & \\
\hline Ac. antimusc. liso & NEG. & & \\
\hline \multicolumn{4}{|l|}{ P. TIREIÓIDEAS } \\
\hline TSH & 6.03 & & \\
\hline T4 livre & 0,98 & & \\
\hline AC. antitireoglobulina & 15,6 & & \\
\hline \multicolumn{4}{|c|}{ PARATIREÓIDES (PTH) } \\
\hline PTH & 54,4 & 43,6 & \\
\hline Ferro & 81 & 70 & \\
\hline Ferritina & 311 & 139 & \\
\hline Transferrina & 102 & 200 & \\
\hline $\mathrm{Cu}$ & 9 & 57 & 80 \\
\hline Ceruloplasmina & 9 & & 22 \\
\hline Zinco & & 81 & \\
\hline Zinco urinário & & 144,1 & \\
\hline Creatinina & 0,71 & & \\
\hline
\end{tabular}




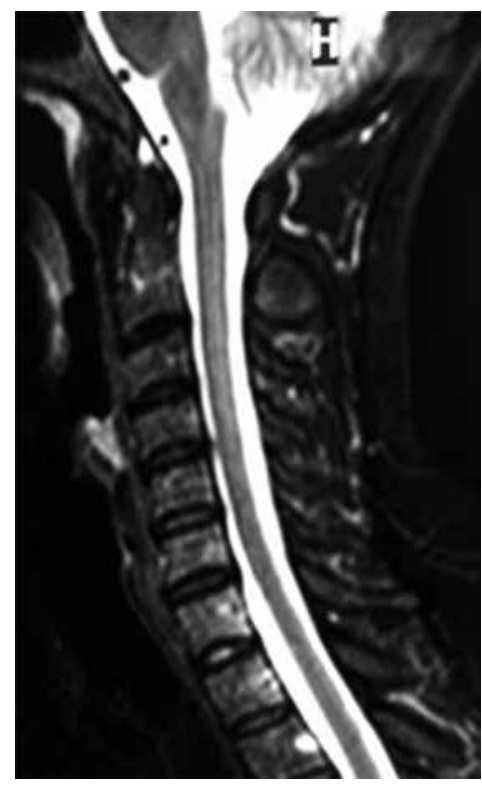

Figura 3 - RNM corte sagital, imagem ponderada T2 após 60 dias de reposição de Cu. Ausência de sinal hiperintenso.

\section{Discussão}

Déficits vitamínicos e transtornos imunológicos e vasculares foram, até o momento, patologias com potencial para desenvolver mielopatias ou mieloneuropatias, segundo descrito em detalhe na literatura científica.

A mielopatia atáxica é descrita em distúrbios de absorção dos ruminantes. ${ }^{3}$ Depois dessas observações, foi plausível reproduzir em ratos neuropatias quando expostos à deficiência na alimentação de $\mathrm{Cu}$.

A doença de Menkes é um defeito ligado a cromossoma X, causado pela mutação no gene ATP7A, que encoda a P-adenosina trifosfatase (MNK), acomete homens e é traduzida como déficit de absorção de $\mathrm{Cu} .{ }^{1,5}$

$\mathrm{O} \mathrm{Cu}$ encontra-se engajado em funções biológicas básicas diversas, sendo consideradas metaloenzimas:

- Zinco-cobre superóxido dismutase (defense antioxidante); dopamina mono-oxigenase (síntese de neurotransmissor);

- Lysyl oxidase (collagen cross-linking, formação de osso);

- Ceruloplasmina (transportador de cobre e ferroxidase);

- Cytochrome c oxidase (transportador de elétrons);

- Factor V(thrombosis);

- Tyrosinase (produção de melatonina).

Em humanos, a absorção gastrointestinal do $\mathrm{Cu}$ se produz na porção superior do trato digestivo alto (estômago e duodeno), por difusão passiva e transporte ativo. Assim, em gastrectomias, cirurgias bariátricas ou técnicas de by-pass intestinal, observa-se potencial para desenvolver absorção inadequada do $\mathrm{Cu}^{2-4}$
$\mathrm{Na}$ ingestão inapropriada de zinco, iatrogênica ou terapêutica (doença de Wilson), a dosagem acima de $50 \mathrm{mg} /$ dia pode comprometer a absorção de cobre e desenvolver anemia, distúrbios da coagulação, hipopigmentação, osteoporose e produção inadequada de colágeno e elastina. ${ }^{1,6,7}$

$\mathrm{O} \mathrm{Zn}$ é transportado intracelularmente tanto de forma ativa como passiva, e baixas concentrações não alteram sua absorção. Já dentro do enterócito se acopla à metalotioneína, cuja concentração é diretamente proporcional à do $\mathrm{Zn}$. Essa metaloproteína tem grande capacidade de se unir a outros cátions bipolares, nesse caso o $\mathrm{Cu}$. Assim, o Cu capturado intracelularmente é indisponibilizado e perdido dentro da luz intestinal por descamação celular fisiológica. ${ }^{3,4,8}$

Por causa do alto índice de absorção do Zn e do reaproveitamento ao longo do intestino, não seriam necessárias grandes doses para manter a homeostase adequada do íon.

Observamos que os complexos multivitamínicos acompanhados de minerais apresentam, na sua composição, zinco acrescentado a seu formulado cobre para contrarrestar o efeito do primeiro.

Nesses compostos, a vitamina $\mathrm{C}$ e a fructuosa têm uma ação inibitória na absorção do $\mathrm{Cu}$, que ocorre por transformar o metal em seu estado reduzido (cuproso) de menor absorção.

Não se deve, porém, desconsiderar a hemodiálise, o leite materno, os quimioterápicos e as doenças inflamatórios crônicas do tubo digestivo, como possíveis causas de hipocupremia.

Acreditamos que manifestações neurológicas por hipocupremia constituem uma síndrome com baixo índice de reconhecimento. As características clínicas observadas mimetizam a deficiência de vitamina B12, sejam clínicas ou radiológicas. Sendo assim, deve-se incluir nas pesquisas laboratoriais a dosagem desse elemento, evitando-se danos neurológicos irreversíveis.

\section{Conflito de interesses}

Os autores declaram inexistência de conflito de interesses na realização deste trabalho.

\section{Referências}

1. Schleper B, Stuerenburg HJ. Copper deficiencyassociated myelopathy in a 46-year-old woman. J Neurol. 2001;248(8):705-6. 
2. Kumar N, McEvoy KM, Ahlskog JE. Myelopathy due to copper deficiency following gastrointestinal surgery. Arch Neurol. 2003;60(12):1782-5.

3. Jaiser SR, Winston GP. Copper deficiency myelopathy. J Neurol. 2010;257(6):869-81.

4. Kumar N. Copper deficiency myelopathy (human swayback). Mayo Clin Proc. 2006;81(10):1371-84.

5. Prodan $\mathrm{Cl}$, Holland NR, Wisdom PJ, Burstein SA, Bottomley SS. CNS demyelination associated with copper deficiency and hyperzincemia. Neurology. 2002;59(9):1453-6.

6. Giovannoni G. Human swayback disease: expanding the spectrum of diseases associated with abnormal copper metabolism. J Neurol. 2001;248(8):707.

7. Winston GP, Jaiser SR. Copper deficiency myelopathy and subacute combined degeneration of the cord - why is the phenotype so similar? Med Hypotheses. 2008;71(2):229-36.
8. Hedera P, Peltier A, Fink JK, Wilcock S, London Z, Brewer GJ. Myelopolyneuropathy and pancytopenia due to copper deficiency and high zinc levels of unknown origin II. The denture cream is a primary source of excessive zinc. Neurotoxicology. 2009;30(6):996-9.

Endereço para correspondência

José Maria Carri

Av. Angélica, 546, ap. 185

01228-000 - São Paulo, SP, Brasil

Telefone: (11) 99285-9666

E-mails: jmcarri@terra.com.br ou jmcarri@me.com 